Article

\title{
Native Quercetin as a Chloride Receptor in an Organic Solvent
}

\author{
Mohamed Lamin Abdi Bellau ${ }^{1}$, Olga Bortolini ${ }^{1}$, Giancarlo Fantin ${ }^{1, *}\left(\mathbb{D}\right.$, Marco Fogagnolo ${ }^{1}(\mathbb{D}$, \\ Daniele Ragno ${ }^{1}$, Ignacio Delso ${ }^{2, *}$ and Pedro Merino ${ }^{3}$ (D) \\ 1 Dipartimento di Scienze Chimiche e Farmaceutiche, Università di Ferrara, Via Luigi Borsari 46, \\ I-44121 Ferrara, Italy; mohamedlamin.abdibellau@unife.it (M.L.A.B.); olga.bortolini@unife.it (O.B.); \\ marco.fogagnolo@unife.it (M.F.); daniele.ragno@unife.it (D.R.) \\ 2 Instituto de Sintesis Quimica y Catalisis Homogenea (ISQCH). Universidad de Zaragoza-CSIC, \\ 50009 Zaragoza, Spain \\ 3 Instituto de Biocomputación y Física de Sistemas Complejos (BIFI), Universidad de Zaragoza, \\ 50009 Zaragoza, Spain; pmerino@unizar.es \\ * Correspondence: fnn@unife.it (G.F.); idelso@unizar.es (I.D.); Tel.: +039-0532-455946 (G.F.)
}

Received: 23 November 2018; Accepted: 18 December 2018; Published: 19 December 2018

\begin{abstract}
The binding properties of quercetin toward chloride anions were investigated by means of ${ }^{1} \mathrm{H}-\mathrm{NMR},{ }^{13} \mathrm{C}-\mathrm{NMR}$, and electrospray ionization mass spectrometry (ESI-MS) measurements, as well as computational calculations. The results indicate that quercetin behaves primarily as a ditopic receptor with the binding site of the $B$ ring that exhibits stronger chloride affinity compared to the A ring. However, these sites are stronger receptors than those of catechol and resorcinol because of their conjugation with the carbonyl group located on the $C$ ring. The 1:1 and 1:2 complexation of this flavonoid with $\mathrm{Cl}^{-}$was also supported by ESI mass spectrometry.
\end{abstract}

Keywords: quercetin; chloride binding; NMR titrations; quantum mechanics density functional theory (QM-DFT) calculations; molecular dynamics (MD) calculations

\section{Introduction}

The search for anion receptors is an important area of supramolecular chemistry due to its importance and potential applications in a wide range of chemical and biological processes [1-5]. Most of these receptors have $\mathrm{N}-\mathrm{H}$ or $\mathrm{N}-\mathrm{H}^{+}$groups contributing to bind anions through $\mathrm{H}$-bonding and/or electrostatic interactions. In other cases, metals or Lewis acids can also act as binding sites [6]. In this framework, small natural products capable of binding and transporting anions, specifically chloride, across hydrophobic membranes are relatively few [7]. The growing interest in molecules that bind and "chaperone" the chloride anion is inspired, in large part, by the knowledge that a number of diseases are caused by the misregulation of this anion across cell membranes [8]. With an eye toward the identification of naturally occurring molecules [9] that could potentially carry out the abovementioned functions, we considered quercetin as a candidate. In fact, this compound possesses hydroxyphenyl moieties for the anion recognition $[10,11]$ and shows affinity to hydrophobic phases such as lipid membranes [12,13]. These considerations prompted us to investigate the binding properties of quercetin toward halides in non-competitive solvents. Moreover, despite many studies on this molecule as ligands for metal cations [14-20], to our knowledge, there are no reports concerning interactions of quercetin with anions.

Quercetin is a naturally occurring polyphenol aglycone, belonging to a group of phytochemicals called polyphenol flavonoids, present in a variety of vegetables and fruits, such as onions, apples, berries, broccoli, tea, and red wine, and is considered a health protective phytonutrient [21]. 
This molecule is, in fact, a potent antioxidant and oxygen radical scavenger, and it is also recognized for having antibacterial, antiviral, antitumoral, and anti-inflammatory properties [22-24].

Quercetin is a 3,5,7,3', $4^{\prime}$-pentahydroxy phenol, having a resorcinol-type arrangement of hydroxyl groups in the A ring and a catechol-type structure in the B ring (Figure 1). In the $\mathrm{C}$ ring, quercetin also contains a 2,3-double bond and 4-oxo function which can give conjugation with the adjacent aromatic rings.

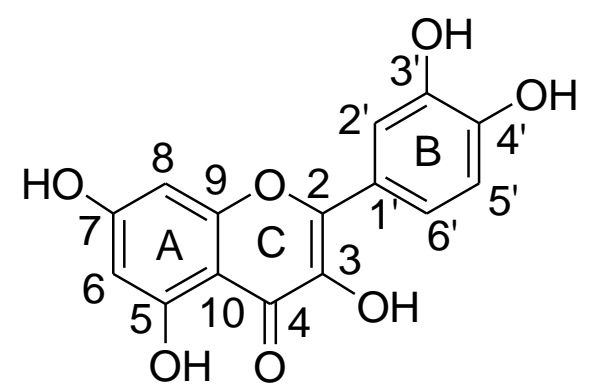

Figure 1. Quercetin (1).

\section{Results and Discussion}

When solid methyltrioctylammonium chloride was added to a solution of quercetin $\mathbf{1}$ in deuterated acetone, the chemical shifts of the corresponding ${ }^{1} \mathrm{H}-\mathrm{NMR}$ spectrum showed dramatic changes. The possibility of aggregation of quercetin was negligible since the ${ }^{1} \mathrm{H}-\mathrm{NMR}$ spectra were substantially identical at concentrations within the range of 1-5 $\mathrm{mM}$ [25]. Consequently, the results clearly indicated an interaction between the chloride anion and this flavonoid.

\section{1. ${ }^{1} H$-NMR Binding Studies}

In order to gather information on the sites and the strength of binding we carried out an ${ }^{1} \mathrm{H}-\mathrm{NMR}$ titration of quercetin with chloride (Figure 2).

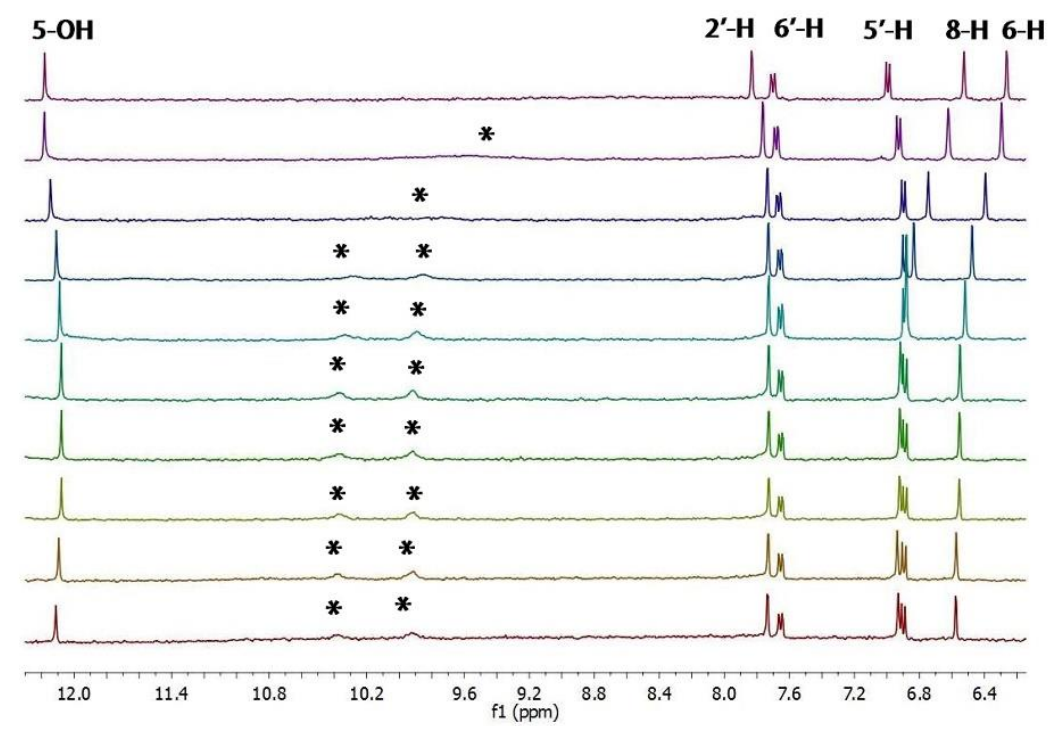

Figure 2. Variations of a portion of ${ }^{1} \mathrm{H}-\mathrm{NMR}$ spectrum (400 $\mathrm{MHz}$ ) of quercetin (1) (concentration $=2.05 \mathrm{mM}$ ) during its titration with chloride. The molar fractions of the guest were 0 , $1.16,2.3,3.4,4.5,6.6,10.7,16.2$, and 27.1 from top to bottom. * indicates $\mathrm{OH}$ groups.

The binding isotherms of the $\mathrm{C}-\mathrm{H}$ protons showed an upfield shift (with hyperbolic trend) for the B-ring protons and a simultaneously more pronounced downfield shift (with sigmoidal shape) for those of the A ring (Figure 3). The behavior of the latter suggests the presence of supplementary 
$\mathrm{C}-\mathrm{H}$-chloride hydrogen-bonding interactions in the A ring [26]. The NMR signals of the OH protons, with the exception of 5-OH, were indistinguishable at the beginning of titration [27]. On the other hand, they became visible during titration by moving downfield (see Figure 2). This fact suggests that the interaction between the chloride anion and these phenolic $\mathrm{OH}$ groups occurs without deprotonation.

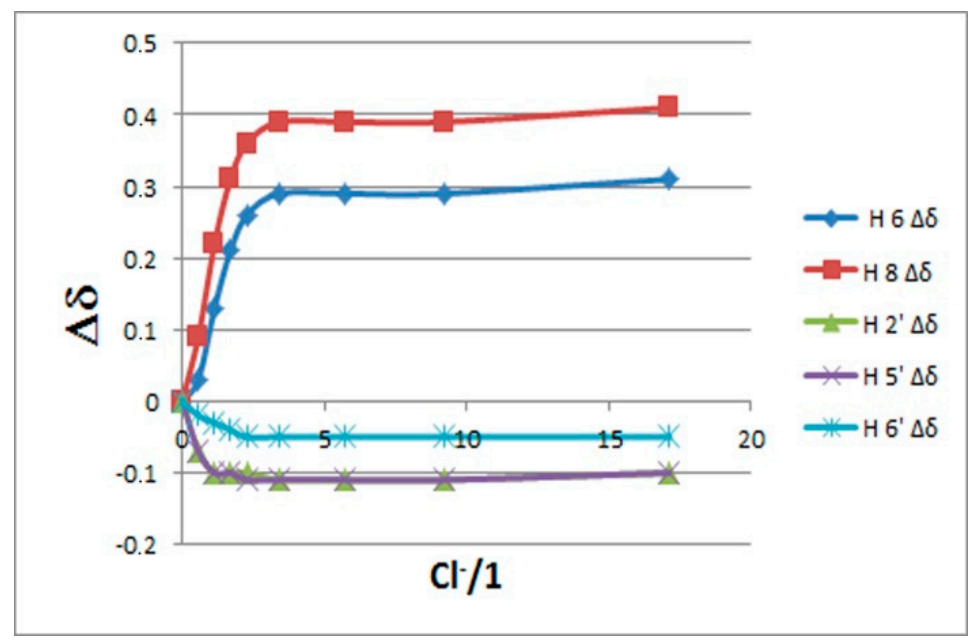

Figure 3. Chemical shifts change of the Ar-H protons of quercetin with increasing $\mathrm{Cl}^{-}$concentration. Positive values mean downfield shifts.

The simultaneous fitting (HypNMR 2008 program [28]) of the saturation curves of Figure 3 achieved by applying both 1:1 and 1:2 binding model gave binding constants with very large uncertainties $(>200 \%)$, suggesting that these results are meaningless. More satisfactory results were obtained considering quercetin as a ditopic receptor and fitting the isotherms of the $\mathrm{A}$ and $\mathrm{B}$ ring separately using a 1:1 binding model [29]; the corresponding binding constants (as Log K values) are reported in Table 1.

Table 1. Binding constants $\beta$ (as Log K) for chloride (as methyltrioctylammonium salt) by hosts 1-2, resorcinol and catechol in acetone- $d_{6}$ at $298 \mathrm{~K}^{\mathrm{a}}$.

\begin{tabular}{ccc}
\hline Host & $\boldsymbol{\beta}\left(\mathbf{M}^{-\mathbf{1}}\right)^{\mathbf{a}}$ from $\mathbf{C H}$ Protons & $\left.\boldsymbol{\beta} \mathbf{( M}^{-\mathbf{1}}\right)^{\mathbf{a}}$ from $\mathbf{O H}$ Protons \\
\hline Quercetin (1) & $\beta_{1}=4.59^{\mathrm{b}}$ (error $\left.=36 \%\right)$ & n.d. ${ }^{\mathrm{c}}$ \\
& $\beta_{2}=2.95^{\mathrm{b}}$ & $\beta_{1}=3.02^{\mathrm{b}}$ \\
1a & $\beta_{1}=3.01^{\mathrm{b}}$ & $\beta_{2}$ n.d. \\
$\mathbf{2}$ & $\beta_{2}$ n.d. & $\beta=3.10$ \\
Catechol & $\beta=3.09$ & $\beta=3.29$ \\
Resorcinol & $\beta=3.36$ & $\beta=2.12$ \\
\hline
\end{tabular}

\footnotetext{
${ }^{a}$ Estimated errors $\leq 10 \%$ unless otherwise stated. ${ }^{\mathrm{b}}$ Binding events on the host were fitted separately as a $1: 1$ single episode. ${ }^{\mathrm{c}}$ Not determined due to signals overlapping.
}

The binding constant obtained for the B ring (catechol moiety) was found to be surprisingly higher than the analog of the catechol ( 4.59 vs. 3.36; see Table 1$)$. This is probably due to the fact that the $B$ ring of quercetin is conjugated to the $C$ ring via an $\alpha, \beta$-unsaturated carbonyl moiety, and this leads to an increase in the acidity of the $4^{\prime}-\mathrm{OH}$ group which is responsible, together with the $3^{\prime}-\mathrm{OH}$ group, for the coordination of the chloride anion in a chelate mode [10].

Anion binding aptitude of the resorcinol moiety (A ring) of quercetin toward the chloride anion is particularly interesting; in this case, in fact, the 5-OH group is "deactivated", due to intramolecular H-bonding with carbonyl group $(\mathrm{C}=\mathrm{O})[30]$, and only the 7-OH group remains available to bind the chloride anion. This feature is clearly verifiable in Figure 2 showing the signal of 5-OH practically unaffected throughout the whole titration. To corroborate this behavior, we performed NMR titrations 
of quercetin diphenylmethylketal 1a and of $2^{\prime}, 4^{\prime}$-dihydroxyacetophenone 2-the first compound containing only the binding site related to the resorcinol moiety and the second one having structural similarities with the A ring of quercetin (Figures 4 and 5). The corresponding binding isotherms, depicted in Figure 6, have a very similar appearance; both the hydroxyl protons ortho to carbonyl group (5-OH of $1 \mathrm{a}$ and 2'-OH of 2) remained unaffected during titration, while the signals of the second $\mathrm{OH}$ (7-OH of 1a and 4'-OH of 2) moved decidedly downfield (this behavior is particularly evident in Figure 5). The signals of the aromatic protons vicinal of the $\mathrm{OH}$ groups (6-H and 8-H of $\mathbf{1 a}$ and $3^{\prime}-\mathrm{H}$, 5'-H of 2) moved downfield by nearly the same magnitude for both receptors; these very significant shifts (between 0.27 and 0.38 ppm, respectively) are indicative of the co-presence of Ar-H-chloride hydrogen-bonding interactions. Moreover, the 3-OH group of the receptor 1a was not significantly perturbed in the ${ }^{1} \mathrm{H}-\mathrm{NMR}$ titration, probably due to an intramolecular hydrogen bond with the carbonyl group, stable enough to withstand the chloride action (Figure 5a).<smiles></smiles>

1a

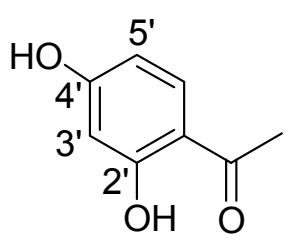

2

Figure 4. Quercetin diphenylmethylketal 1a and 2', $4^{\prime}$-dihydroxyacetophenone 2.
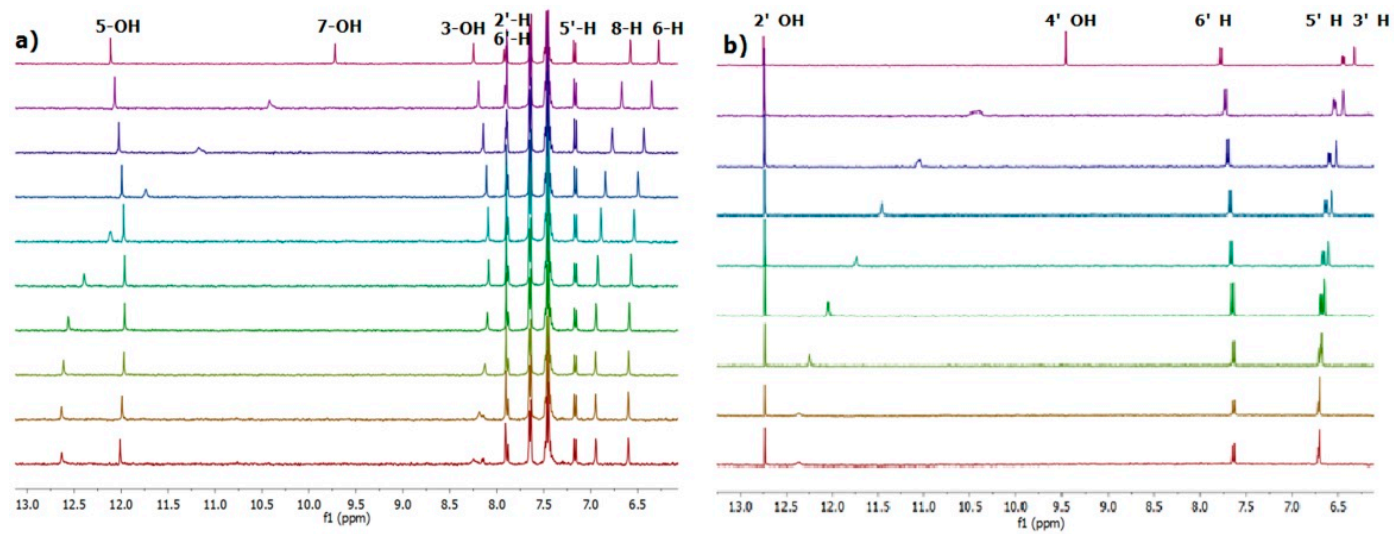

Figure 5. (a) Variations of a portion of ${ }^{1} \mathrm{H}-\mathrm{NMR}$ spectrum $(400 \mathrm{MHz})$ of $\mathbf{1 a}(2 \mathrm{mM})$ during its titration with chloride. The molar fractions of the guest were $0,0.99,1.96,2.91,3.85,5.66,9.09,23.08,28.86$, and 34.31 from top to bottom. (b) Variations of a portion of ${ }^{1} \mathrm{H}-\mathrm{NMR}$ spectrum $(400 \mathrm{MHz})$ of $2(2 \mathrm{mM})$ during its titration with chloride. The molar fractions of the guest were $0,1.02,2.02,2.99,3.95,5.83$, $9.36,14.19$, and 23.75 from top to bottom. 


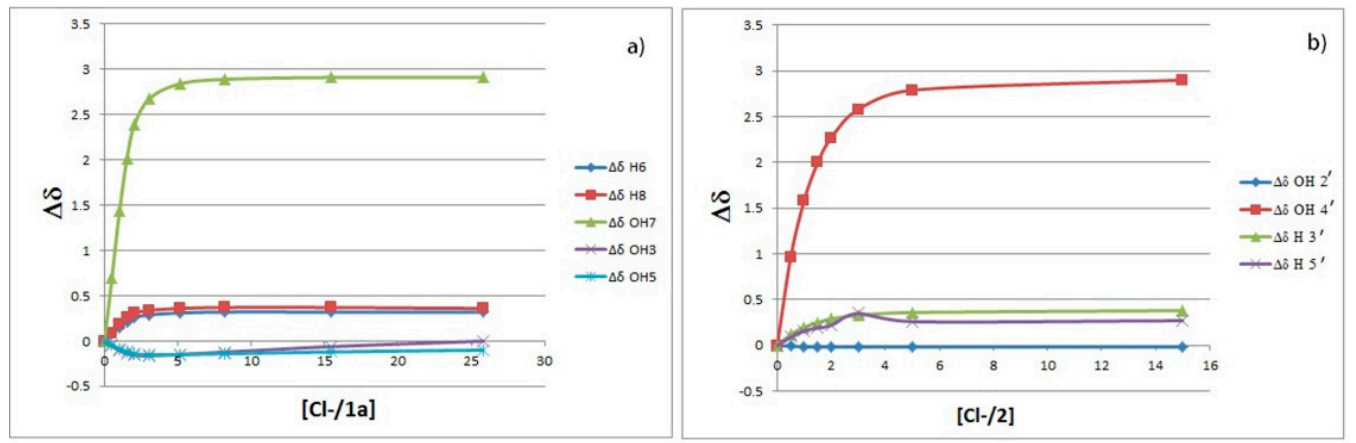

Figure 6. (a) Change in ${ }^{1} \mathrm{H}$ chemical shifts of 1a with increasing $\mathrm{Cl}^{-}$concentration. (b) Change in ${ }^{1} \mathrm{H}$ chemical shifts of 2 with increasing $\mathrm{Cl}^{-}$concentration. Positive values mean downfield shifts.

Data analysis fitted the 1:1 binding profile and gave a Log K of 3.02 for receptor 1a and of 3.1 for receptor 2.

In order to have a point of reference, binding constants of catechol and resorcinol $(2 \mathrm{mM})$ in deuterated acetone and methyltrioctylammonium chloride as titrants were also carried out. The magnitude of these constants, $\log \mathrm{K}=3.36 \mathrm{M}^{-1}$ for the catechol and $\log \mathrm{K}=2.39 \mathrm{M}^{-1}$ for the resorcinol, were consistent with the results of Smith (in $\mathrm{CD}_{3} \mathrm{CN}$ ) [10].

It is interesting to note that $\mathbf{1 a}$ and $\mathbf{2}$ were found to be more effective receptors than the resorcinol probably due to a $-\mathrm{M}$ mesomeric effect of the carbonyl group engaged in a intramolecular $\mathrm{C}=\mathrm{O} \cdots \mathrm{H}-\mathrm{O}$ hydrogen bond that increases the acidity of the para $\mathrm{OH}$ group, as well as that of the adjacent aromatic protons. Indeed, it was reported that the $\mathrm{pK}_{\mathrm{a} 1}$ value for resorcinol is 9.5 [31], while that calculated for $2^{\prime}, 4^{\prime}$-dihydroxyacetophenone (2) is significantly lower at 7.9 [32]. A lower $\mathrm{pK}_{\mathrm{a}}$ value is consistent with a greater capability of acting as hydrogen-bond donors.

The binding attitude of quercetin to bromide was also studied (for details, see Supplementary Materials). As expected [10], the binding strength of quercetin for bromide $\left(\beta_{1}=1.62 \mathrm{M}^{-1}\right.$; $\beta_{2}=1.61 \mathrm{M}^{-1}$ ) was significantly smaller than that displayed toward chloride (see Table 1 ). It is interesting to note that catechol moiety showed a significant degree of dimensional selectivity for the chloride and bromide anions ( $\beta_{1}=4.59$ vs. $1.62 \mathrm{M}^{-1}$, respectively), about three orders of magnitude. In the case of the resorcinol moiety, however, the chloride was only bound a factor of ca. 10 stronger than bromide ( $\beta_{1}=2.95$ vs. $1.61 \mathrm{M}^{-1}$, respectively), thus indicating a much lower degree of size selectivity. Similar trend of dimensional selectivity for the chloride and bromide anions, although less pronounced, was also observed for the individual catechol and resorcinol molecules [10].

\section{2. ${ }^{13} \mathrm{C}-\mathrm{NMR}$ and ESI-MS Binding Studies}

We compared the maximum perturbation caused by an excess (25 equiv.) of chloride anion on the ${ }^{13} \mathrm{C}$-NMR chemical shifts of quercetin, catechol, and $2^{\prime}, 4^{\prime}$-dihydroxyacetophenone $(20 \mathrm{mM}$ in acetone) (Figure 7). Figure 7a shows that the complexation-induced shifts (CISs) on the B-ring carbons of quercetin and on the carbons of the structurally analogous catechol have a very similar trend; therefore, it can be stated that very similar bond interactions occur between the chloride and each receptor. Similar CISs were also observed for the carbons belonging to the A ring of quercetin and for the analogous carbons of $2^{\prime}, 4^{\prime}$-dihydroxyacetophenone (Figure $7 \mathrm{~b}$ ). This indicates that the interactions of the chloride anion with the A ring of the quercetin and the $2^{\prime}, 4^{\prime}$-dihydroxyacetophenone are very similar. 


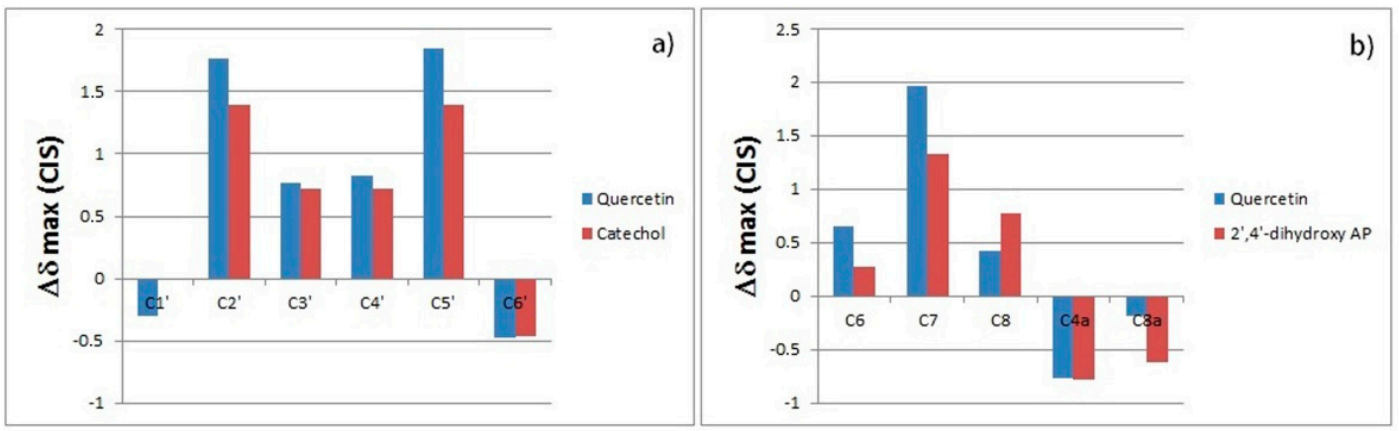

Figure 7. (a) $\Delta \delta_{\max }$ of the carbons of the B ring of quercetin compared with analogous carbons of catechol after addition of an excess of chloride anion. (b) $\Delta \delta_{\max }$ of carbons of the A ring of quercetin compared with analogous carbons of $2^{\prime}, 4^{\prime}$-dihydroxyacetophenone after addition of an excess of chloride anions. Positive values mean downfield shifts. All spectra were run at a concentration of $20 \mathrm{mM}$.

Binding interactions between quercetin and chloride anion were also confirmed by electrospray negative-ion mass spectrometry (ESI-MS) which revealed a peak corresponding to the 1:1 complex $\left(1 \cdots \mathrm{Cl}^{-}\right)$at $\mathrm{m} / z 337(25 \%)$, and a base peak at $\mathrm{m} / z 740$ relative to the 1:2 complex $\left(\mathrm{Me}(\mathrm{Octyl})_{3} \mathrm{~N}^{+} \mathrm{Cl}^{-} \cdots \mathbf{1} \cdots \mathrm{Cl}^{-}\right.$) (See Figure S9, Supplementary Materials).

\subsection{Molecular Modeling}

The complexes of quercetin with chloride anion were examined using density functional theory (DFT) calculations (for details, see Supplementary Materials). The structure of quercetin was minimized. Then we studied 1:1 chloride complexes, and three relative energy minima were found for each structure in which the chloride anion was positioned at the resorcinol moiety, at the catechol moiety, and at the proximities of the 3-hydroxyl group. The most stable geometry corresponded to the complex where the chloride anion was located at the catechol moiety, predicting $100 \%$ of abundance due to the observed difference in energy. The optimized geometry of this minimum is shown in Figure 8a. In the case of 2:1 chloride complexes, a unique minimum with chloride anions located at the resorcinol and catechol moieties was found (Figure $8 b$ ). Strong directional interactions were observed between chloride anions and hydroxyl groups in agreement with spectroscopic observations. Non-covalent interaction (NCI) analyses confirmed such interactions as typical green-blue discs featuring strong non-covalent interactions.

a)
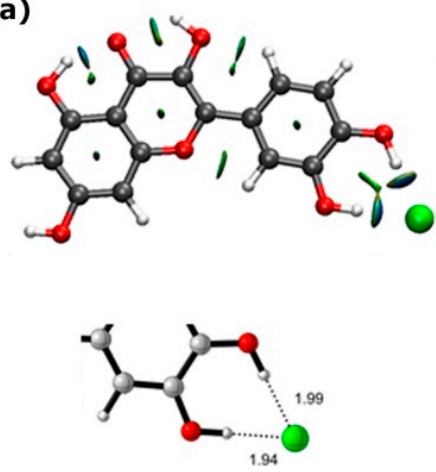

$[1 \cdot \mathrm{Cl}]^{-}$
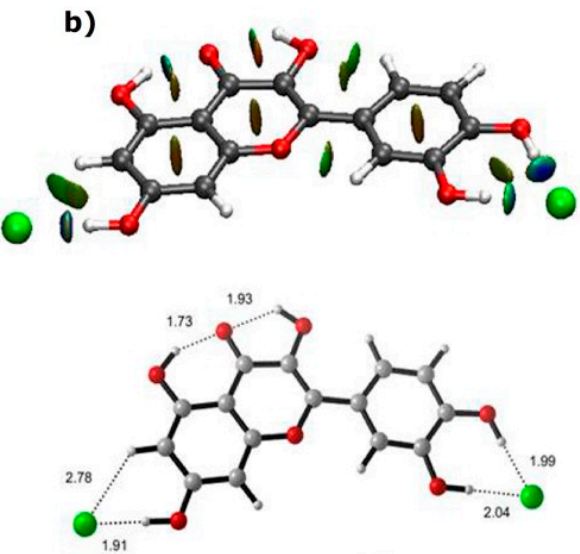

$[1 \cdot 2 \mathrm{Cl}]^{-2}$

Figure 8. Optimized geometries, showing non-covalent interaction (NCI) surfaces: (a) 1:1 complex of chloride anion with quercetin; (b) 2:1 complex of chloride anion with quercetin. Details are given with distances indicated in ångström. 
To study the dynamics of the recognition process, molecular dynamics (MD) simulations were performed with AMBER16 and AMBERTools16. Relevant interaction distances between oxygen atoms and chloride anions were followed during the simulation (Figure 9).

a)
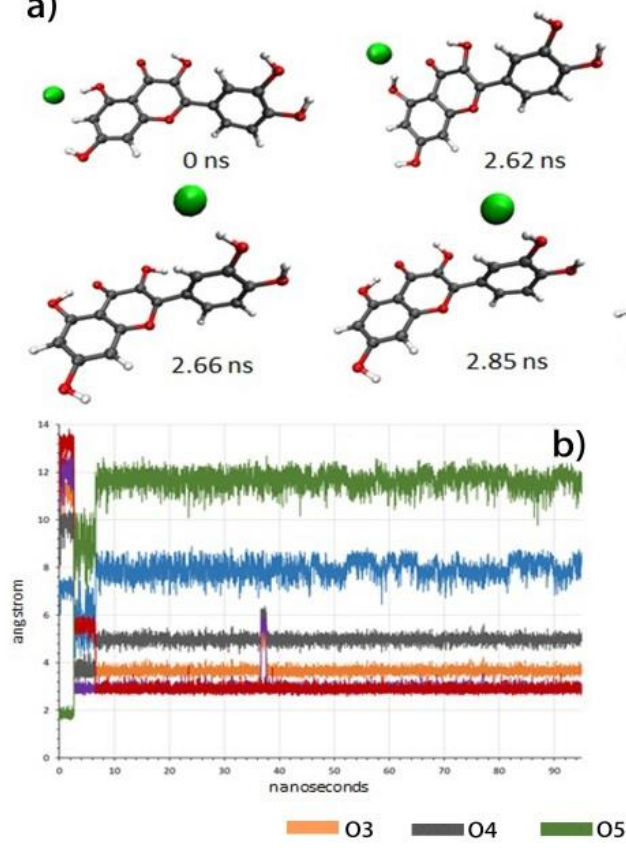

b)

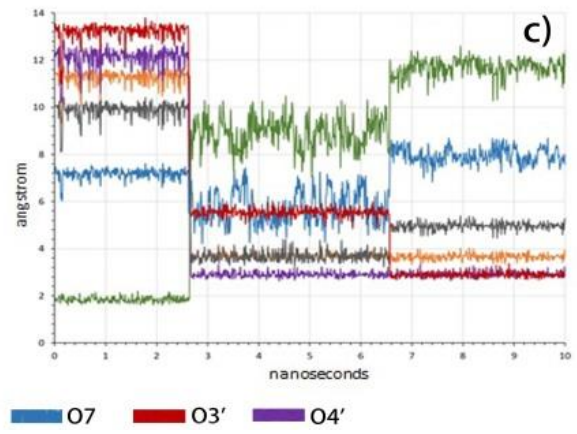

Figure 9. (a,b) Interaction distances between oxygen atoms and chloride anions during the simulation starting from the chloride anion located at the resorcinol moiety; (c) expansion of the first $10 \mathrm{~ns}$ of subfigure (b).

When the MD started, considering the complex where the chloride anion was placed at the resorcinol moiety, the system evolved and a snapshot taken after 2.65 ns showed the chloride in the proximity of O3. Further snapshots showed the movement of chloride toward the catechol and, after $6.60 \mathrm{~ns}$, the complex at the catechol was raised. As expected, when the chloride anion was placed at the catechol moiety, it remained in the proximity of $\mathrm{O}^{\prime}$ and $\mathrm{O}^{\prime}$, reflecting the stability of the complex. These results clearly established the recognition by the catechol moiety as the most stable, in agreement with experimental observations.

With a second chloride anion, the situation remained completely stable with chloride anions located at resorcinol and catechol moieties (See Figure S12, Supplementary Materials), as predicted by DFT calculations and in good agreement with experimental observations.

\section{Materials and Methods}

\subsection{General Comments}

All the reagents and solvents used in this study were bought from commercial sources. The NMR spectra were recorded in acetone- $d_{6}$ solvent using 5 -mm tubes, at $298 \mathrm{~K}$, with a Varian Mercury Plus 400, (Varian Inc., Palo Alto, CA, USA) operating at $400\left({ }^{1} \mathrm{H}\right)$ and $100 \mathrm{MHz}\left({ }^{13} \mathrm{C}\right)$. The chemical shifts were referenced to acetone: $\delta(\mathrm{H}) 2.04 \mathrm{ppm}$ and $\delta(\mathrm{C}) 29.0 \mathrm{ppm}$. Some ${ }^{13} \mathrm{C}-\mathrm{NMR}$ spectra were acquired in non-deuterated acetone; in this case, a capillary filled with $\mathrm{C}_{6} \mathrm{D}_{6}$ (secondary standard [33]) was placed into the 5-mm tube and the sample was locked and shimmed on $\mathrm{C}_{6} \mathrm{D}_{6}$ contained in the secondary standard, and the chemical shifts were also referenced to $\mathrm{C}_{6} \mathrm{D}_{6}: \delta(\mathrm{C}) 127.6 \mathrm{ppm}$. ESI mass spectra were obtained using an LCQ Duo (ThermoQuest, San Jose, CA, USA) in negative-ion mode. Instrumental parameters were as follows: capillary voltage $-10 \mathrm{~V}$, spray voltage $4.50 \mathrm{kV}$, mass scan range was from 
$m / z 100$ to $2000 \mathrm{amu}$, for 30,000 ms of scan time; $\mathrm{N}_{2}$ was used as sheath gas. The samples were injected into the spectrometer through a syringe pump at a constant flow rate of $8 \mathrm{~mL} / \mathrm{min}$.

\section{2. ${ }^{1} \mathrm{H}-\mathrm{NMR}$ Titration}

The following is a typical procedure for ${ }^{1} \mathrm{H}-\mathrm{NMR}$ titration: $1 \mathrm{~mL}$ of a $2 \mathrm{mM}$ solution of host in undried acetone- $d_{6}$ [34] was placed in a $5-\mathrm{mm}$ NMR tube and an initial spectrum was taken. A measured amount of a $100 \mathrm{mM}$ solution of guest (as methyl trioctylammonium salt) in the same solvent was added, changing the molar fraction of guest to about $0,0.5,1,1.5,2,3,5,10,20$, and 30 . Spectra were recorded after each addition. The chemical shift variation of the host signals was collected and the binding constants $\beta$ (as Log K) were calculated with the curve-fitting method [35] using the commercial HypNMR2008 [28] program (details are given in Supplementary Materials).

\section{Conclusions}

In summary, the anion-binding properties of the natural flavonoid quercetin in an organic solvent for chloride anions were studied using spectroscopic (NMR and MS) and computational (DFT and MD) methods.

We demonstrated that quercetin, in the NMR titrations, behaves as a ditopic receptor at the A and $B$ rings; in fact, no significant shifts of the $C$ ring protons occur. It is interesting to note that the affinity of the resorcinol moiety of quercetin and of its diphenymethylketal derivative $\mathbf{1 a}$ for chloride anions is found to be similar to that of $2^{\prime}, 4^{\prime}$-dihydroxyacetophenone 2 , which in turn is greater than that of simple resorcinol. Furthermore, the bond constant obtained for the B ring (catechol moiety) is surprisingly high, about seventeen times greater than the catechol analog. This is probably due to the fact that the $B$ ring of quercetin is conjugated to the $C$ ring via an $\alpha, \beta$-unsaturated carbonyl group.

Supplementary Materials: The supplementary materials are available online.

Author Contributions: G.F.: Conceptualization; Data curation; Formal analysis; Visualization; Writing-review \& editing. M.L.A.B.: Investigation. O.B.: Project administration; Validation. M.F.: Conceptualization; Writing - original draft. D.R.: Investigation; Resources. I.D.: Formal analysis; Visualization. P.M.: Data curation; Validation; Writing-original draft.

Funding: We gratefully acknowledge the University of Ferrara (fondi FAR) for its financial support.

Acknowledgments: Thanks are also given to P. Formaglio for NMR spectroscopic experiments and to T. Bernardi for mass spectrometric experiments. I.D. and P.M. acknowledge the MINECO and FEDER Program (Madrid, Spain, project CTQ2016-76155-R) and the Gobierno de Aragon (Zaragoza, Spain. Biological \& Computational Chemistry Group. E34_R17). The authors thankfully acknowledge the resources from the supercomputers "Memento" and "Cierzo", and the technical expertise and assistance provided by BIFI-ZCAM (Universidad de Zaragoza, Spain).

Conflicts of Interest: The authors declare no conflicts of interest.

\section{References and Notes}

1. Gale, P.A.; Howe, E.N.W.; Wu, X. Anion receptor chemistry. Chem 2016, 1, 351-422. [CrossRef]

2. Gale, P.A.; Garcia-Garrido, S.E.; Garric, J. Anion receptors based on organic frameworks: Highlights from 2005 and 2006. Chem. Soc. Rev. 2008, 37, 151-190. [CrossRef] [PubMed]

3. Oshovsky, G.V.; Reinhoudt, D.N.; Verboom, W. Supramolecular Chemistry in Water. Angew. Chem. Int. Ed. 2007, 46, 2366-2393. [CrossRef] [PubMed]

4. Gunnlaugsson, T.; Glynn, M.; Tocci, G.M.; Kruger, P.E.; Pfeffer, F.M. Anion recognition and sensing in organic and aqueous media using luminescent and colorimetric sensors. Coord. Chem. Rev. 2006, 250, 3094-3117. [CrossRef]

5. Sessler, J.L.; Camiolo, S.; Gale, P.A. Pyrrolic and polypyrrolic anion binding agents. Coord. Chem. Rev. 2003, 240,17-55. [CrossRef]

6. Gale, P.A. Anion receptor chemistry: Highlights from 1999. Coord. Chem. Rev. 2001, 213, 79-128. [CrossRef]

7. Davis, J.T.; Okunola, O.; Quesada, R. Recent advances in the transmembrane transport of anions. Chem. Soc. Rev. 2010, 39, 3843-3862. [CrossRef] [PubMed] 
8. Rowe, S.M.; Miller, S.; Sorscher, E.J. Cystic Fibrosis. N. Engl. J. Med. 2005, 352, 1992-2001. [CrossRef]

9. Fantin, G.; Fogagnolo, M.; Delso, I.; Merino, P. Exploratory spectroscopic and computational studies of the anion binding properties of methyl hyocholate in organic solvent. Tetrahedron 2017, 73, 1698-1704. [CrossRef]

10. Winstanley, K.J.; Sayer, A.M.; Smith, D.K. Anion binding by catechols an NMR, optical and electrochemical study. Org. Biol. Chem. 2006, 4, 1760-1767. [CrossRef]

11. Winstanley, K.J.; Smith, D.K. Ortho-substituted catechol derivatives: The effect of intramolecular hydrogen-bonding pathways on chloride anion recognition. J. Org. Chem. 2007, 72, 2803-2815. [CrossRef] [PubMed]

12. Van Dijk, C.; Driessen, A.; Recourt, K. The uncoupling efficiency and affinity of flavonoids for vesicles. Biochem. Pharmacol. 2000, 60, 1593-1600. [CrossRef]

13. Pawlikowska-Pawlęga, B.; Gruszecki, W.I.; Misiak, L.; Paduch, R.; Piersiak, T.; Zarzyka, B.; Pawelec, J.; Gawron, A. Modification of membranes by quercetin, a naturally occurring flavonoid, via its incorporation in the polar head group. Biochim. Biophys. Acta 2007, 1768, 2195-2204. [CrossRef]

14. De Souza, R.F.V.; De Giovani, W.F. Antioxidant properties of complexes of flavonoids with metal ions. Redox Rep. 2004, 9, 97-104. [CrossRef] [PubMed]

15. Naso, L.; Valcarcel, M.; Villacé, P.; Roura-Ferrer, M.; Salado, C.; Ferrer, E.G.; Williams, P.A.M. Specific antitumor activities of natural and oxovanadium (IV) complexed flavonoids in human breast cancer cells. $N$. J. Chem. 2014, 38, 2414-2421. [CrossRef]

16. Parveen, S.; Tabassum, S.; Arjmand, F. Human topoisomerase I mediated cytotoxicity profile of L-valine-quercetin diorganotin (IV) antitumor drug entities. J. Organomet. Chem. 2016, 823, 23-33. [CrossRef]

17. Hong, M.; Yin, H.; Zhang, X.; Li, C.; Yue, C.; Cheng, S. Di- and tri-organotin (IV) complexes with 2-hydroxy-1-naphthaldehyde 5-chloro-2-hydroxybenzoylhydrazone: Synthesis, characterization and in vitro antitumor activities. J. Organomet. Chem. 2013, 724, 23-31. [CrossRef]

18. Tabassum, S.; Yadav, S. Investigation of diorganotin (IV) complexes: Synthesis, characterization, in vitro DNA binding studies and cytotoxicity assessment of di-n-butyltin (IV) complex. Inorg. Chim. Acta 2014, 423, 204-214. [CrossRef]

19. Tabassum, S.; Zaki, M.; Afzal, M.; Arjmand, F. New modulated design and synthesis of quercetin-CuII/ZnII-Sn2 IV scaffold as anticancer agents: In vitro DNA binding profile, DNA cleavage pathway and Topo-I activity. Dalton Trans. 2013, 42, 10029-10041. [CrossRef]

20. Dell'Anna, M.M.; Censi, V.; Carrozzini, B.; Caliandro, R.; Denora, N.; Franco, M.; Veclani, D.; Melchior, A.; Tolazzi, M.; Mastrorilli, P. Triphenylphosphane Pt (II) complexes containing biologically active natural polyphenols: Synthesis, crystal structure, molecular modeling and cytotoxic studies. J. Inorg. Biochem. 2016, 163, 346-361. [CrossRef]

21. Kaur, C.; Kapoor, H.C. Antioxidants in fruits and vegetables-The millennium's health. Int. J. Food Sci. Technol. 2001, 36, 703-725. [CrossRef]

22. Massi, A.; Bortolini, O.; Ragno, D.; Bernardi, T.; Sacchetti, G.; Tacchini, M.; De Risi, C. Research progress in the modification of quercetin leading to anticancer agents. Molecules 2017, 22, 1270. [CrossRef] [PubMed]

23. Rice-Evans, C.A.; Miller, J.; Paganga, G. Antioxidant properties of phenolic compounds. Trends Plant Sci. 1997, 2, 152-159. [CrossRef]

24. Harborne, J.B.; Williams, C.A. Advances in flavonoid research since 1992. Phytochemistry 2000, 55, 481-504. [CrossRef]

25. Zhao, Y.; Ryu, E.-H. Solvent-tunable binding of hydrophilic and hydrophobic guests by amphiphilic molecular baskets. J. Org. Chem. 2005, 70, 7585-7591. [CrossRef] [PubMed]

26. Berryman, O.B.; Sather, A.C.; Hay, B.P.; Meisner, J.S.; Johnson, D.W. Solution phase measurement of both weak $\sigma$ and $\mathrm{C}-\mathrm{H} \cdots \mathrm{X}$ - hydrogen bonding interactions in synthetic anion receptors. J. Am. Chem. Soc. 2008, 130, 10895-10897. [CrossRef]

27. Charisiadis, P.; Kontogianni, V.G.; Tsiafoulis, C.G.; Tzakos, A.G.; Siskos, M.; Ioannis, P.; Gerothanassis, I.P. ${ }^{1} \mathrm{H}-\mathrm{NMR}$ as a structural and analytical tool of intra- and intermolecular hydrogen bonds of phenol-containing natural products and model compounds. Molecules 2014, 19, 13643-13682. [CrossRef]

28. Frassineti, C.; Ghelli, S.; Gans, P.; Sabatini, A.; Moruzzi, M.S.; Vacca, A. Nuclear magnetic resonance as a tool for determining protonation constants of natural polyprotic bases in solution. Anal. Biochem. 1995, 231, 374-382. [CrossRef] 
29. Lowe, A.J.; Long, B.M.; Pfeffer, F.M. Examples of regioselective anion recognition among a family of two-, three-, and four-"Armed" bis-, tris-, and tetrakis(thioureido)[n]polynorbornane hosts. J. Org. Chem. 2012, 77, 8507-8517. [CrossRef]

30. Leopoldini, M.; Marino, T.; Russo, N.; Toscano, M. Density functional computations of the energetic and spectroscopic parameters of quercetin and its radicals in the gas phase and in solven. Theor. Chem. Acc. 2004, 111, 210-216. [CrossRef]

31. Herrero-Martínez, J.M.; Sanmartin, M.; Rosés, M.; Bosch, E.; Ràfols, C. Determination of dissociation constants of flavonoids by capillary electrophoresis. Electrophoresis 2005, 26, 1886-1895. [CrossRef] [PubMed]

32. Calculated using Advanced Chemistry Development (ACD/Labs) Software V11.02 (C1994-2018 ACD/Labs.).

33. Lenevich, S.; Distefano, M.D. NMR-based quantification of organic diphosphates. Anal. Biochem. 2011, 408, 316-320. [CrossRef] [PubMed]

34. Ca. 20-30 eq. of water were present during NMR titrations. (Estimated by integration of the water peak in the deuterated acetone).

35. Fielding, L. Determination of association constants (Ka) from solution NMR data. Tetrahedron 2000, 34, 6151-6170. [CrossRef]

Sample Availability: Samples of the compounds are not available from the authors. 